\title{
Effect of organic compounds on nanoparticle formation in diluted diesel exhaust
}

\author{
U. Mathis ${ }^{1}$, M. Mohr ${ }^{1}$, and R. Zenobi ${ }^{2}$ \\ ${ }^{1}$ EMPA, Swiss Federal Laboratories for Materials Testing and Research, Laboratory for Internal Combustion Engines, \\ CH-8600 Dübendorf, Switzerland \\ ${ }^{2}$ ETH Hönggerberg, Swiss Federal Institute of Technology, Chemistry Department, CH-8093 Zürich, Switzerland
}

Received: 6 November 2003 - Published in Atmos. Chem. Phys. Discuss.: 8 January 2004

Revised: 2 April 2004 - Accepted: 2 April 2004 - Published: 15 April 2004

\begin{abstract}
The nucleation of nanoparticles in the exhaust of a modern light-duty diesel vehicle was investigated on a chassis dynamometer. This laboratory study is focused on the influence of volatile organic compounds (VOCs) on nucleation of volatile nanoparticles. Different organic compounds were added to the dilution air of the particle sampling under different sampling conditions. Sample temperature and relative sample humidity were varied in a wide range. The number size distribution of the particles was measured with a scanning mobility particle sizer (SMPS) and showed significant differences in response to the added organic compounds. While the nucleation mode particles showed a large variation in concentration, the accumulation mode particles remained unchanged for all compounds. Depending on the functional group, organic compounds were capable of initiating and increasing (alcohols and toluene) or decreasing (acetone, aniline, and methyl tert-butyl ether (MTBE)) nucleation mode particles. Short volatile aliphatic hydrocarbons (hexane and cyclohexane) turned out to be without effect on nucleation of nanoparticles. Possible reasons for the differences are discussed.
\end{abstract}

\section{Introduction}

Exhaust from diesel engines represents an important anthropogenic source of particles in ambient air. Particles from internal combustion engines can be divided into solid and volatile particles (Kittelson, 1998). The solid particles mainly consist of agglomerated carbonaceous primary particles, which are usually described as soot. However, other compounds such as hydrocarbons can be adsorbed or condensed on its surface. The volatile nanoparticles are usually formed by nucleation of sulfuric acid, water, and other

Correspondence to: $\mathrm{M}$. Mohr

(martin.mohr@empa.ch) species. Formation of these volatile nanoparticles strongly depends on the dilution and cooling process of the exhaust. The two different kinds of particles usually form separate modes in the number size distribution, that are referred to as "accumulation mode" and "nucleation mode".

Adverse health effects of particles on human health have been documented in several studies (Pope, 2000; Petrovic et al., 2000; Oberdörster, 2001). Impact on health has mainly been studied for soot particles and thus, there is limited information about volatile nanoparticles. Because volatile nanoparticles have a distinctly smaller diameter than soot particles, the mass contribution of volatile nanoparticles is usually small. However, investigations have documented that health effects were more related to particle number than to mass (Donaldson et al., 1998; Sydbom et al., 2001) even though the current legislation for particle emissions is based on mass. Compared to soot a higher deposition rate in the lungs might be expected for volatile nanoparticles because of their smaller diameters. As indicated in a study by Kim and Jaques (2000), the deposition rate of $40 \mathrm{~nm}$ solid nanoparticles is nearly 2.5 times higher than for $100 \mathrm{~nm}$ nanoparticles. To assess the human health impact of volatile nanoparticles, more information about their exact composition is needed. Sulfuric acid seems to be a relevant compound for human health effects in volatile nanoparticles. Inhalation of acid aerosols in laboratory animal studies causes genotoxic damage in cells (Soskolne et al., 1984; Swenberg and Beauchamp, 1997). Kilgour et al. (2002) showed cell proliferation of the respiratory tract in rats due to exposure to sulfuric acid.

Improvements in engine technologies have reduced particle mass emissions from diesel engines. The limit values for mass emissions from light-duty diesel vehicles were gradually reduced by more than four times from $0.18 \mathrm{~g} \mathrm{~km}^{-1}$ (Euro 1 , since 1992) to $0.025 \mathrm{~g} \mathrm{~km}^{-1}$ (Euro 4 , as of 2005). A reduction in mass is related to a decrease in number of soot particles, but there is no clear relation to the volatile nanopar- 


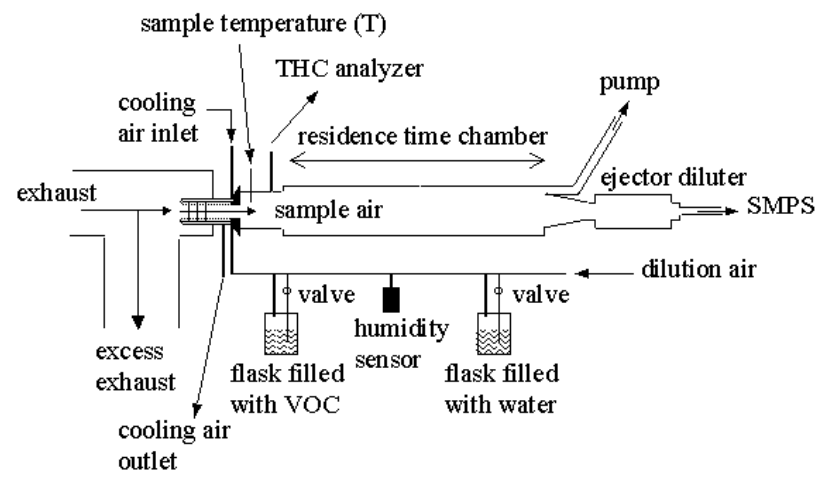

Fig. 1. Overview of the experimental set-up.

Table 1. Engine parameters of the vehicle.

\begin{tabular}{ll}
\hline displacement per cylinder & $1896 \mathrm{~cm}^{3}$ \\
number of cylinder & 4 \\
maximum power / rpm & $81 \mathrm{~kW} / 4150 \mathrm{~min}^{-1}$ \\
aftertreatment system & oxidation catalyst \\
model year & 1999 \\
\hline
\end{tabular}

ticle emissions (Mohr et al., 2001). It is generally accepted that volatile nanoparticles are influenced by dilution parameters such as temperature, dilution ratio, residence time, and humidity (Abdul-Khalek et al., 1999; Khalek et al., 2000; Mathis, 2002). In addition, the fuel sulfur content plays an important role (Ntziachristos et al., 2000; Maricq et al., 2002). Volatile nanoparticles are observed in both laboratory and vehicle chasing experiments, but the observed nucleation mode in chasing studies could not have been reproduced in laboratory control experiments yet (Kittelson, 2002; Vogt et al., 2003). A possible explanation could be the high sensitivity of the nucleation mode to the dilution parameters. Kittelson (1998) reported that a dilution ratio of 1000 is typical for an atmospheric dilution process of exhaust. However, large variation in atmospheric dilution depending on driving and ambient conditions is observed. The dilution parameters can be better controlled in laboratory experiments, which guarantees a stable dilution process. A dilution ratio of 1000 is difficult to apply for many laboratory studies due to the high requirements of exact dilution parameters control. Although a lower dilution ratio is often applied in laboratory studies than under real world conditions, the formation mechanism of volatile nanoparticles is expected to be the same. Therefore, laboratory studies contribute to a better understanding of the principles in the formation process of volatile nanoparticles in real world conditions.

If the concentration of soot particles is sufficiently large, volatile nanoparticles can be quenched. Moreover, preexisting soot particles scavenge a part of the volatile nanopar-
Table 2. Fuel analysis of the diesel.

\begin{tabular}{llr}
\hline analysis & unit & result \\
\hline sulfur & $\mathrm{ppm}$ & 323 \\
cetan index & - & 49.1 \\
density at $15^{\circ} \mathrm{C}$ & $\mathrm{kg} \mathrm{m}^{-3}$ & 831 \\
viscosity at $40^{\circ} \mathrm{C}$ & $\mathrm{mm}^{2} \mathrm{~s}^{-1}$ & 2.41 \\
flash point & ${ }^{\circ} \mathrm{C}$ & 62.5 \\
aromatics & volume-\% & 24.7 \\
\hline
\end{tabular}

ticles by collision (Seinfeld and Pandis, 1998). As the total surface provided by soot particles is reduced, the relevant species responsible for nucleation remain in the gaseous phase and can lead to homogeneous nucleation (Kittelson, 1998; Mohr et al., 2001). However, the classical binary nucleation theory of water and sulfuric acid underestimates the formation of nucleation mode particles by several orders in number and thus, further species are suspected to be involved in nucleation (Shi and Harrison, 1999; Khalek et al., 2000). Besides the explanation of classical binary homogeneous nucleation of sulfuric acid and water in diesel exhaust, homogeneous ternary nucleation of sulfuric acid, ammonia, and water (Napari et al., 2002) or nanoparticle formation from chemiions generated during combustion (Yu, 2001; Yu, 2002) were reported. Organic compounds are often considered as the key species to control the growth of nucleation mode particles (Maricq et al., 1999; Kerminen et al., 2000; Khalek et al., 2000; Zhang and Wexler, 2002). Analytical investigations of the volatile nanoparticles in diesel exhaust has given strong indications that organic compounds were involved in the nucleation process (Tobias et al., 2001; Sakurai et al., 2003). The role of organic compounds has been investigated in more detail for the formation of cloud condensation nuclei $(\mathrm{CCN})$ than for the dilution process of engine exhaust. The organic compounds found in $\mathrm{CCN}$ are mainly organic acids such as formic, acetic, pyruvic, pinonic oxalic, and malonic acids (Yu, 2000; Hegg et al., 2001; Giebl et al., 2002). Little is known about organics with other functional groups. We investigated how non-acid organic compounds are involved in the nucleation process of volatile particles in diluted diesel exhaust. We added a variety of VOCs (aliphatic hydrocarbons, aromatic compounds, a ketone, an amine, an ether, and alcohols) into the primary dilution air. The intention of this laboratory study is to contribute to a better understanding of organic compounds in the nucleation process of diluted diesel exhaust. The focus of this laboratory study is to identify the functional groups that are involved in the nucleation process. 


\section{Experimental}

\subsection{Vehicle and fuel}

All experiments were conducted with a modern light-duty diesel vehicle on a chassis dynamometer at constant speed $\left(50 \mathrm{~km} \mathrm{~h}^{-1}\right)$ and increased load conditions $(7.0 \pm 0.2 \mathrm{~kW}$, $18.1 \pm 0.5 \%$ of maximum power, $2100 \mathrm{rpm}$ ). The normal load was $2 \mathrm{~kW}$ under road conditions. The engine parameters and the results of fuel analysis are listed in Table 1 and Table 2. The tests were run with a standard fuel with a sulfur concentration of $323 \mathrm{ppm}$. The main advantage of using a diesel fuel with high sulfur content was the stable and repeatable formation of volatile nanoparticles, which was the prerequisite for our investigation. The additional sulfur contribution in the exhaust by lube oil consumption was estimated to be $6 \mathrm{ppm}$ fuel equivalent. The vehicle was running at $7.0 \pm 0.2 \mathrm{~kW}$ load for at least $20 \mathrm{~min}$ to conditionate the vehicle and sampling system.

\subsection{Sampling}

The overall set-up of the particle measurement is shown in Fig. 1. The relevant nucleation parameters such as dilution ratio, dilution temperature, and residence time were kept constant. Dilution of the exhaust sample was performed with a two-stage dilution unit. The primary dilution of the exhaust was accomplished inside a porous tube (Dekati prototype), which was inserted directly into the tailpipe to minimize sampling losses. Detailed information about the diluter can be found in Mikkanen et al. (2001). By controlling the temperature of the dilution air by means of a vortex cooler, the sample temperatures $(\mathrm{T})$ were in the range of $34.7^{\circ} \mathrm{C} \pm 0.5^{\circ} \mathrm{C}$ or $44.5^{\circ} \mathrm{C} \pm 0.5^{\circ} \mathrm{C}$, respectively. The sample temperature was measured immediately after the first dilution. The dilution ratio was set to $8.5 \pm 0.5$ by the flow ratio of the dilution air to the raw exhaust. Downstream of the first dilution stage unit, a residence chamber was inserted, offering sufficient time for the relevant nucleation compounds to nucleate. A constant residence time of $2.50 \pm 0.15 \mathrm{~s}$ was chosen. The second dilution unit was placed at the end of the residence chamber to quench the formation and growth of nucleation mode particles. The dilution ratio of this ejector dilution unit remained constant at 10 . Our dilution ratios for the primary and the secondary dilution are in line with similar studies conducted in this field (Abdul-Khalek et al., 1999; Maricq et al., 1999; Tobias et al., 2001; Sakurai et al., 2003).

To vary humidity in the exhaust sample, a part of the dilution air of the primary diluter was bubbled through a flask filled with de-ionized water before entering the porous tube diluter. Relative humidity of the dilution air ranged from $4 \%$ to $75 \%$, measured by a humidity sensor (Rotronic BM90). The chamber temperature was controlled and only ranged from $24.0^{\circ} \mathrm{C}$ to $25.5^{\circ} \mathrm{C}$. This temperature recorded was taken into account for the calculation of the relative sample humid- ity. Further contributions to the humidity came from combustion of the diesel fuel and the combustion air. Calculation of the combustion air humidity was based on a typical diesel fuel elemental composition of $14 \%$ hydrogen and $86 \%$ carbon. The combustion air was measured to be $50 \%$ relative humidity at $25^{\circ} \mathrm{C}$ and $950 \mathrm{hPa}$. Taking all contributions into account, the relative sample humidity after the first dilution unit was calculated to range from $30 \%$ to $99 \%$ at the measured sample temperature. The relative sample humidity is hereafter referred to as relative humidity (RH). To adjust the gas concentration of the selected organic compounds in the sample, the pure organic compounds were filled into an additional flask as shown in Fig. 1. Some of the liquid organic compounds filled in the flask could uptake water from the dilution air and reduce the relative humidity of the dilution air. This effect was considered to be negligible in this study. All added organic compounds were of technical quality (Fluka). Control experiments by evaporating the organic compounds and de-ionized water in the flask showed no particle formation: The dilution air enriched with the organic compounds and water was analyzed by a scanning mobility particle sizer (SMPS, TSI) without observing any particles in the number size distribution. Concentrations of the organic compounds added to the exhaust were measured with a flame ionization detector (FID, Horiba Mexa-7400H) after the first dilution and were normalized to the effective number of carbon. The FID was calibrated with propane in the linear region from $1 \mathrm{ppm}$ to $5000 \mathrm{ppm}$ corrected as $\mathrm{C}_{1}$. When the concentration exceeded the concentration of $5000 \mathrm{ppm}$ corrected as $\mathrm{C}_{1}$, we present the data as larger than the highest measured concentration corrected for the added organic compound (e.g. $>5600$ ppm toluene in Fig. 6, top panel).

\subsection{Particle number size distribution}

A SMPS, consisting of a differential mobility analyzer (DMA, TSI 3071) and a condensation particle counter (CPC, TSI 3025), was used for determining the number size distribution of the particles. The DMA had a polydisperse inlet flow of $1.51 \mathrm{~min}^{-1}$ and a sheath air flow of $151 \mathrm{~min}^{-1}$ that selected particle diameters ranged from $7 \mathrm{~nm}$ to $214 \mathrm{~nm}$. The impactor upstream of the DMA was removed because the pressure drop was too high to properly operate the CPC. A bypass to the DMA $\left(4.81 \mathrm{~min}^{-1}\right)$ was installed to increase the flow rate and reduce diffusion losses. Therefore, no correction of diffusion losses was conducted.

\subsection{Calculation of the organic vapor concentration}

Based on the FID measurements, the vapor pressure $p_{i}$ of the substance $i$ in the sample air was calculated according to the ideal gas equation:

$p_{i}=\frac{\left(c_{i, p p m}-c_{\text {background }, \text { ppm }}\right) \cdot 10^{-6}}{M_{v}} R \cdot T$, 


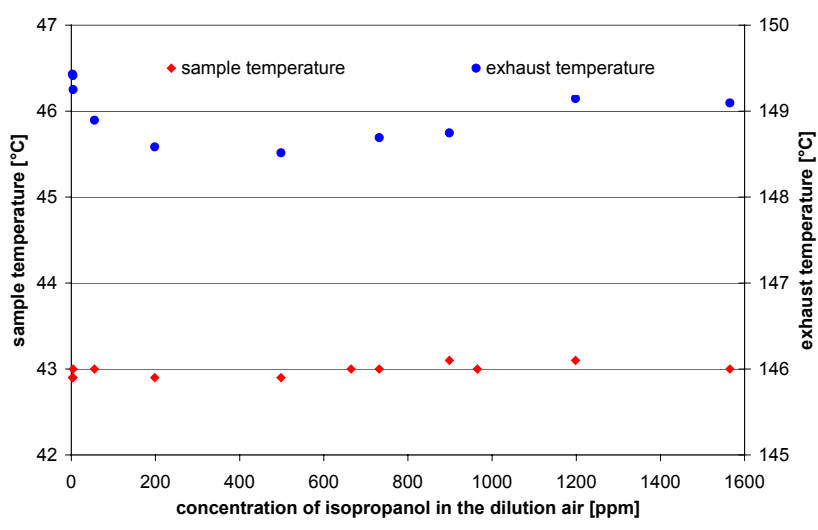

Fig. 2. Variation of sample and exhaust temperatures as a function of the 2-propanol concentration in the sample air.

where $R$ is the universal gas constant $\left(8.3145 \mathrm{~J} \mathrm{~mol}^{-1} \mathrm{~K}^{-1}\right)$, $T$ is the chamber temperature measured in Kelvin, $c_{i, p p m}$ is the volume concentration in ppm of the substance $i$, $c_{\text {background,ppm is }}$ is concentration without adding any VOCs, and $M_{v}$ is the mole volume. c cackground,ppm was measured experimentally to be $5 \mathrm{ppm}$ for all measurements.

The vapor pressure $P_{S i}$ in Torr over the pure liquid phase for a flat surface was calculated for the substance $i$ according to the Antoine equation (Lange and Dean, 1973):

$\log _{10} P_{S i}=A-\frac{B}{C+t}$,

or alternatively, for 1-butanol with

$\log _{10} P_{S i}=C-\frac{52.23 \cdot B}{(t+273.15)}$,

where $A, B$, and $C$ are constants and $t$ is the temperature in ${ }^{\circ} \mathrm{C}$.

The constants $A, B$, and $C$ were taken from Lange and Dean (1973). For 1-hexanol and MTBE the values were taken from Poling et al. (2001) and Krähenbühl and Gmehling (1994), respectively.

To compare the vapor pressures with each other, a common quantity was introduced. A good approach is the saturation ratio $S_{i}$; the ratio of the partial vapor pressure $p_{i}$ to the saturation vapor over the pure liquid phase $P_{S i}$ :

$S_{i}=\frac{p_{i}}{P_{S i}}$.

\section{Results and discussions}

The aim of this investigation was to study a selection of VOCs on the nucleation process at varying temperature and humidity of the sample. Because the nucleation process is very sensitively to small changes of the dilution conditions, it had to be verified that the increase of humidity and VOCs in the dilution air did not influence any sampling parameters. Regarding the key parameters listed in Table 3, the variations of the sampling parameters are small within a test series. The variations from one test to another mainly depended on the restart of the vehicle. To unambiguously assign the effect of VOCs, the influence of the other key parameters were recorded. A typical temperature variation of the dilution flow, sample flow, and exhaust flow within the same test series is shown for 2-propanol in Fig. 2. Variations of temperatures were randomly distributed and were not dependent on the concentration of 2-propanol in the dilution air. Based on these control experiments, it was verified that an increase of humidity and VOCs did not influence the sampling parameters.

The variation of the accumulation mode was found to vary $\pm 25 \%$ from one test series to another when the vehicle was restarted. A possible reason could be the corresponding vehicle load variation of $\pm 3 \%$ at this very sensitive operation point. In line with the load variation the exhaust temperature varied $\pm 6^{\circ} \mathrm{C}$. A small exhaust temperature variation can be responsible to alter the conversion rate from $\mathrm{SO}_{2}$ to $\mathrm{SO}_{3}$ by the oxidation catalyst. Nevertheless, the load could be set within $\pm 1 \%$ for a test series that provided stable test conditions without any significant effect on the accumulation mode particles. Therefore, we consider the test-to-test variation as uncritical since the interpretation of our data is based on relative changes within a test series.

To investigate at which step of nucleation VOCs have an impact, three test conditions $\mathrm{A}, \mathrm{B}$, and $\mathrm{C}$ were evaluated. The key nucleation parameters of these three conditions are presented in Table 3. Tests without any addition of VOC revealed the following results: Under test condition A (sample temperature $(\mathrm{T})=44.9^{\circ} \mathrm{C}$, relative humidity $(\mathrm{RH})=36.3 \%$ ) no or only a weak nucleation mode could be detected. Under condition $\mathrm{B}\left(\mathrm{T}=44.3^{\circ} \mathrm{C}, \mathrm{RH}=81.2 \%\right)$ a nucleation was always observed, which is explained by the higher humidity compared to condition $\mathrm{A}\left(\mathrm{T}=44.9^{\circ} \mathrm{C}, \mathrm{RH}=36.3 \%\right)$. The strongest nucleation occurred under condition $\mathrm{C}\left(\mathrm{T}=34.7^{\circ} \mathrm{C}\right.$, $\mathrm{RH}=31.6 \%$ ) as the low dilution air temperature provoked nucleation already at low humidity levels.

\subsection{Effect of humidity}

To distinguish the effect of humidity and VOCs in the dilution air on the nucleation process, a first series was conducted varying only the humidity in the dilution air. The sample temperature was either held at $45.0^{\circ} \mathrm{C}$ or at $34.2^{\circ} \mathrm{C}$. Figure 3 depicts the effect of humidity on nucleation under both conditions. A considerable humidity effect on the nucleation mode particles was found at a sample temperature of $45.0^{\circ} \mathrm{C}$. When the humidity was increased, a strong rise of the nucleation mode particles was observed. In addition, this peak moved to slightly higher diameters with increasing humidity. This can be explained by stronger coagulation due to a higher concentration of volatile nanoparticles at $99 \%$ 
Table 3. Average and standard deviation of the key parameters for all test series.

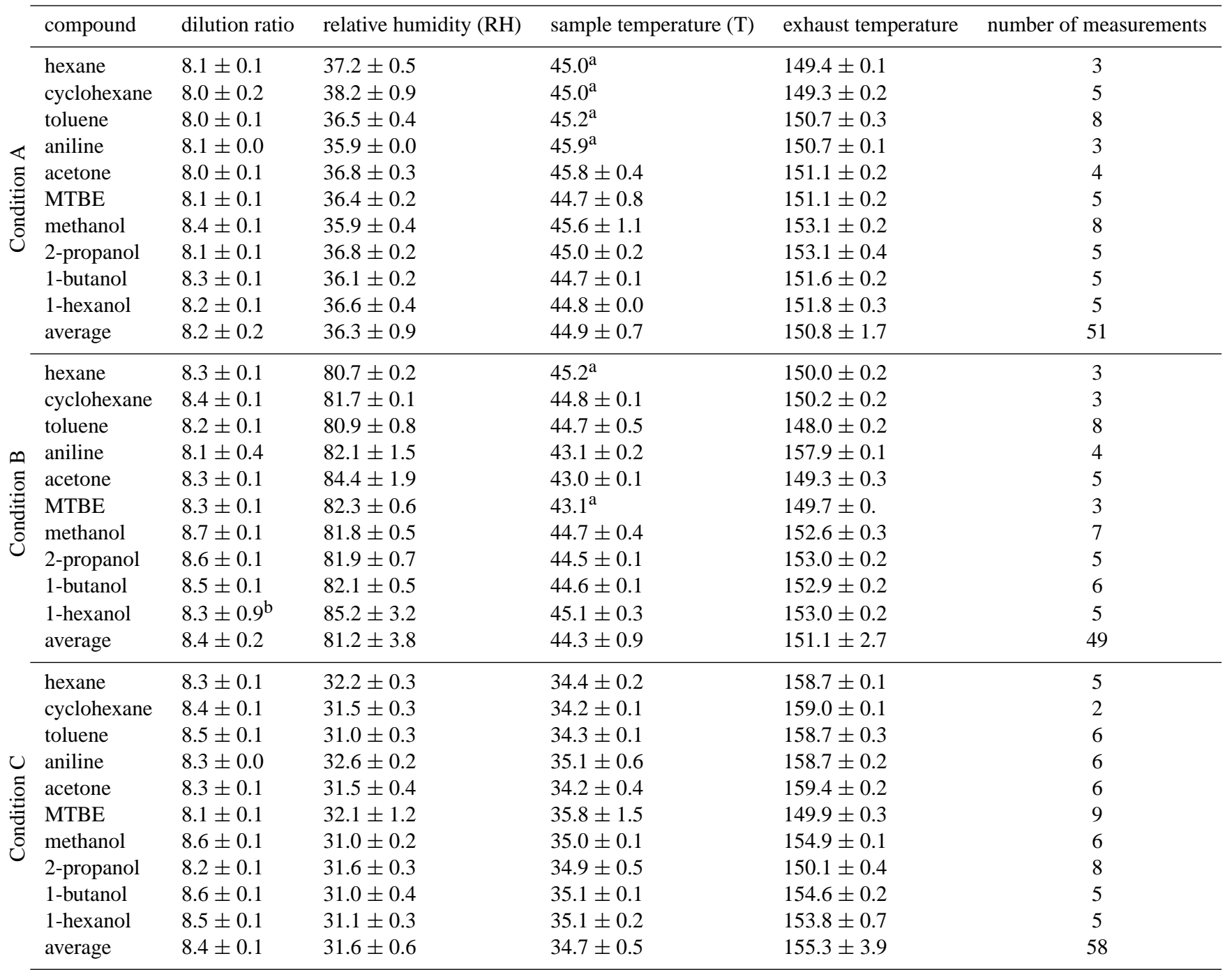

a The dilution temperature was only once measured during the whole test and thus, no deviation is indicated.

${ }^{b}$ Bigger deviation was due to the lower dilution ratio of 6.7 in the first scan.

relative humidity. The accumulation mode remained stable at about $70 \mathrm{~nm}$. There was a distinct nucleation mode under dry conditions at $31 \%$ relative humidity and a sample temperature of $34.2^{\circ} \mathrm{C}$. The nucleation mode particles increased by a factor of two when the relative humidity was increased from $31 \%$ to $81 \%$. In comparison with the sample temperature at $45.0^{\circ} \mathrm{C}$, there was a considerably lower influence of humidity on the nucleation process. To compare the strength of nucleation, the ratio of the maximum number concentrations in the nucleation mode to the accumulation mode was calculated. Due to this normalization, no correction of the particle number size distribution by the dilution ratio was necessary. This ratio is presented as a function of the relative humidity in the sample in Fig. 4. Below about $60 \%$ relative humidity, no appreciable nucleation took place at a sample temperature of $45.0^{\circ} \mathrm{C}$, indicating a minimal initial relative humidity for nucleation. As soon as the relative humidity was further increased, a clear dependence on humidity was observed. The ratio of the maximum number concentrations of nucleation mode to the accumulation mode showed a linear dependence on the humidity over the entire investigated range at a sample temperature of $34.2^{\circ} \mathrm{C}$. The lower sensitivity on humidity at a sample temperature of $34.2^{\circ} \mathrm{C}$ is apparent when the slope is compared under the assumption of linear response. The sample temperature at $45.0^{\circ} \mathrm{C}$ with a slope of $0.062(\%$ relative humidity $)^{-1}$ had a significantly steeper slope than at $34.2^{\circ} \mathrm{C}$ with a slope of $0.037(\% \text { relative humidity })^{-1}$. In spite of the bigger humidity effect on the volatile nanoparticles at a sample temperature of $45.0^{\circ} \mathrm{C}$, the absolute concentration of volatile nanoparticles was always higher at $34.2^{\circ} \mathrm{C}$. Our ex- 

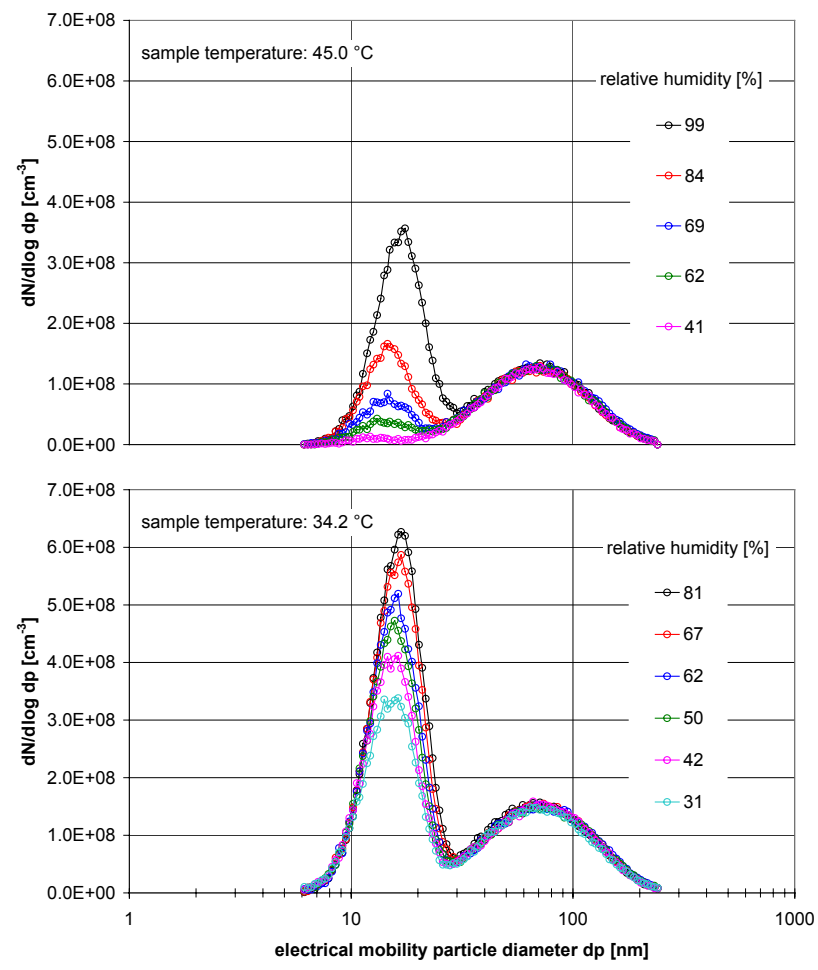

Fig. 3. Influence of humidity on the nucleation mode. A weak nucleation was detected at the lowest relative humidity of $41 \%$ and sample temperature $45.0^{\circ} \mathrm{C}$ (top panel). The nucleation increased more than one order of magnitude when the relative humidity increased to $99 \%$. For the sample temperature $34.2^{\circ} \mathrm{C}$ a nucleation mode was observed even with the lowest relative humidity $31 \%$ (bottom panel). Therefore, the increase of nucleation was less pronounced than at sample temperature $45.0^{\circ} \mathrm{C}$.

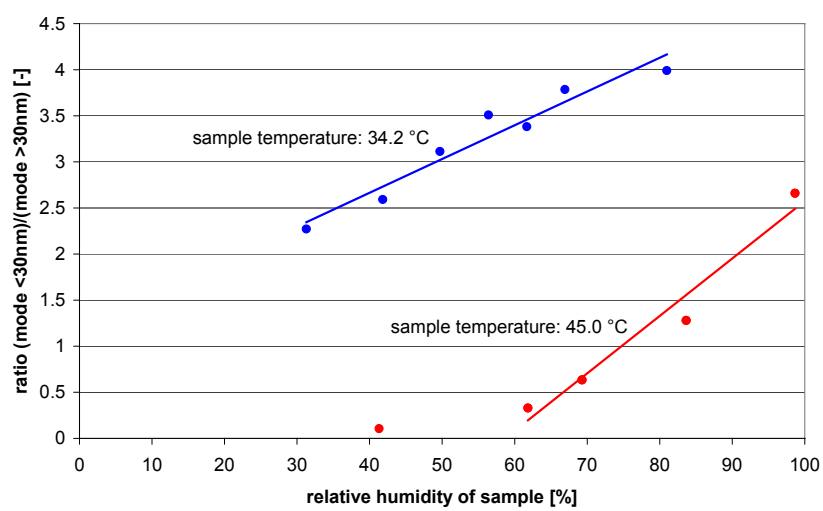

Fig. 4. Strength of nucleation for variable humidity. The linear regression in the linear region resulted in a correlation factor of $\mathrm{R}^{2}=0.94$ and $\mathrm{R}^{2}=0.96$ at sample temperature $34.2^{\circ} \mathrm{C}$ and $45.0^{\circ} \mathrm{C}$, respectively.

perimental work is in accordance with the parametric study of Kim et al. (2002). A linear dependence was found of the nucleation rate as a function of relative humidity under conditions of increased humidity.
Table 4. Molecular structure of the investigated organic compounds.

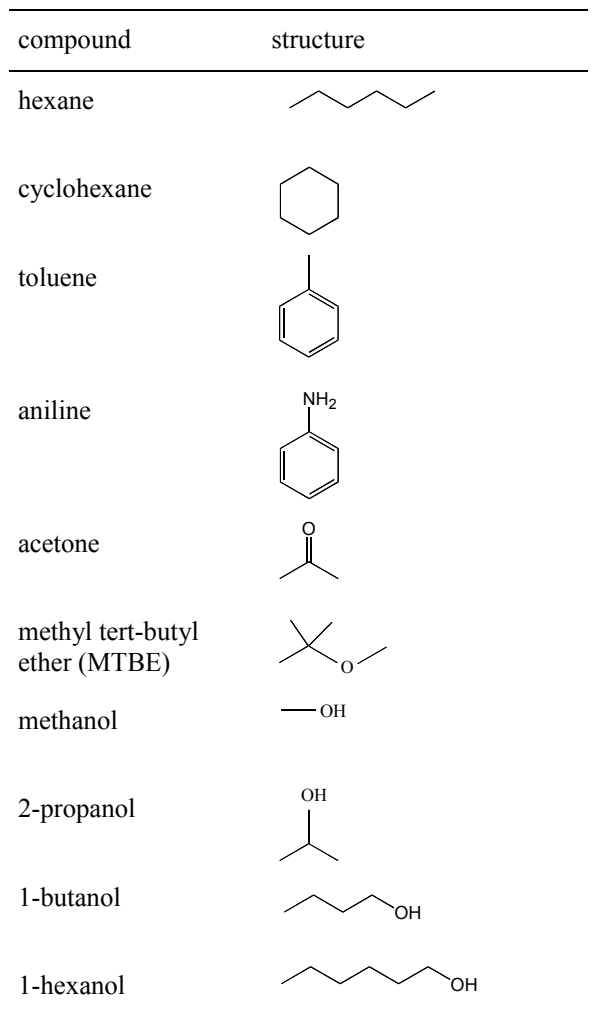

\subsection{Effect of organic vapors on the nucleation mode}

To find out which substance classes affect the nucleation process, a variety of organic compounds were added. The measured hydrocarbon concentration corrected as $\mathrm{C}_{1}$ ranged from $500 \mathrm{ppm}$ to $5000 \mathrm{ppm}$ in the mixed sample part and exceeded the normal concentrations in exhaust gas by one or two orders of magnitude. However, concentrations of several thousands ppm are typical for cold starts at low temperatures. We found raw gas concentrations of $5000 \mathrm{ppm}$ to $20000 \mathrm{ppm}$ and $10000 \mathrm{ppm}$ to $30000 \mathrm{ppm}$ for diesel and gasoline vehicles, respectively, in the first minutes of cold starts at $-20^{\circ} \mathrm{C}$. Since we operated the engine at warm conditions, the oxidation catalyst converted hydrocarbons to a large extent. However, we do not intend to simulate the real world situation at this engine operation point but to gain a principal understanding of the nucleation process in presence of organic compounds. The added chemical compounds consisted of aliphatic hydrocarbons, aromatic compounds, a ketone, an amine, an ether, and alcohols. The chemical structures of these compounds are shown in Table 4 . We chose compounds of high volatility to prevent losses by condensation on the sampling system. We are aware that less volatile organic compounds are more likely to be in- 
hexane

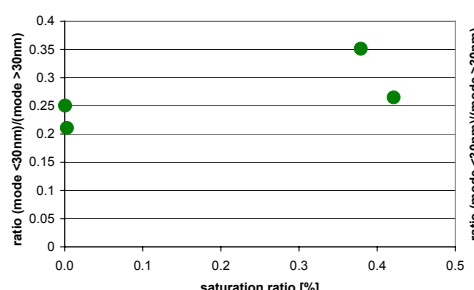

cyclohexane

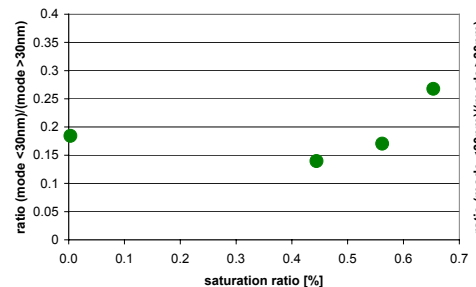

toluene
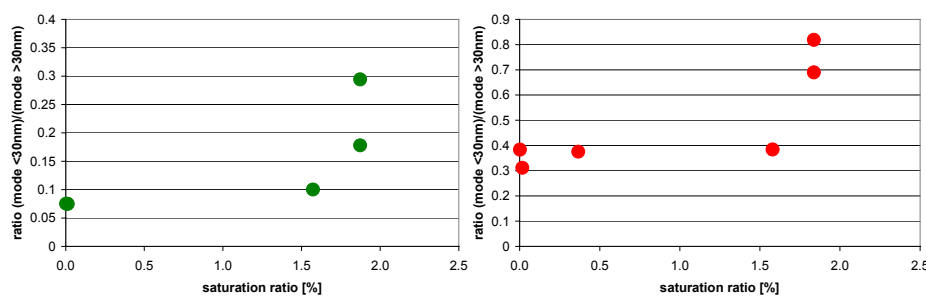

aniline
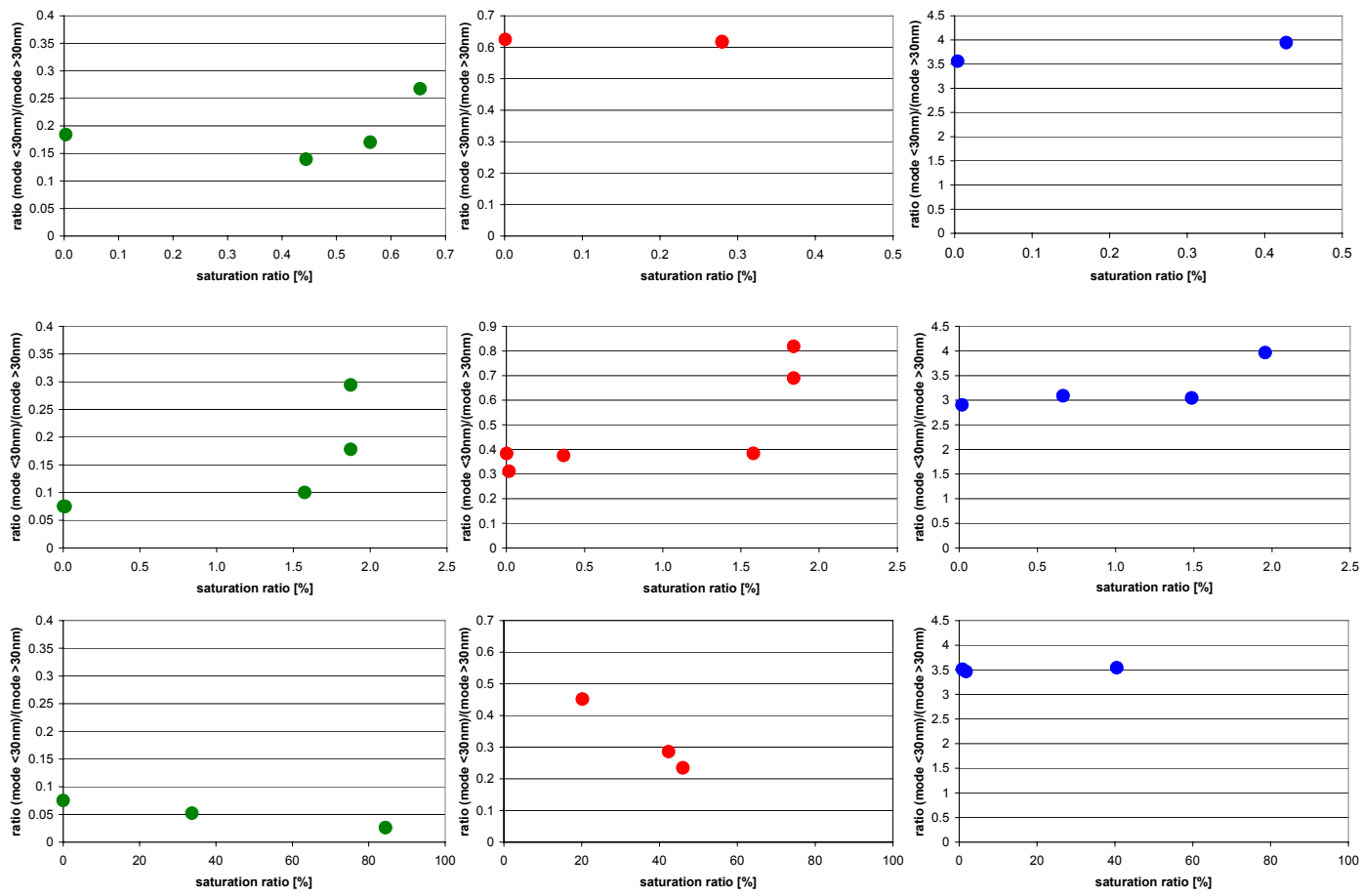

acetone
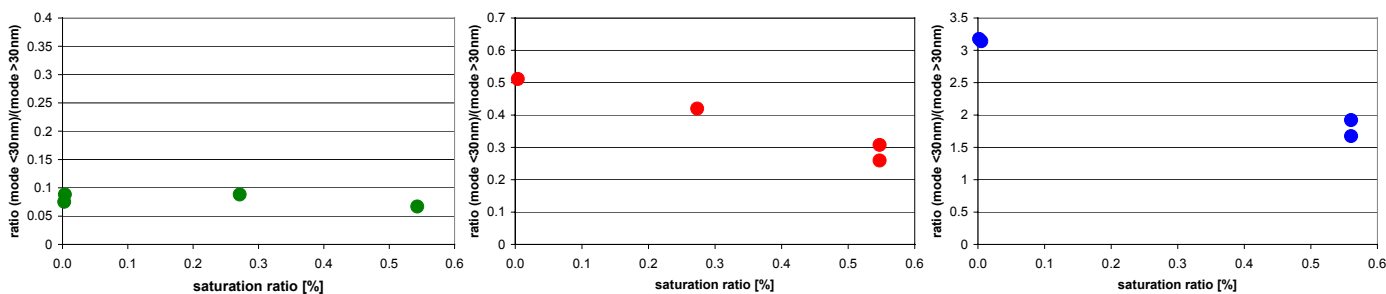

methyl tert-

butyl ether

(MTBE)
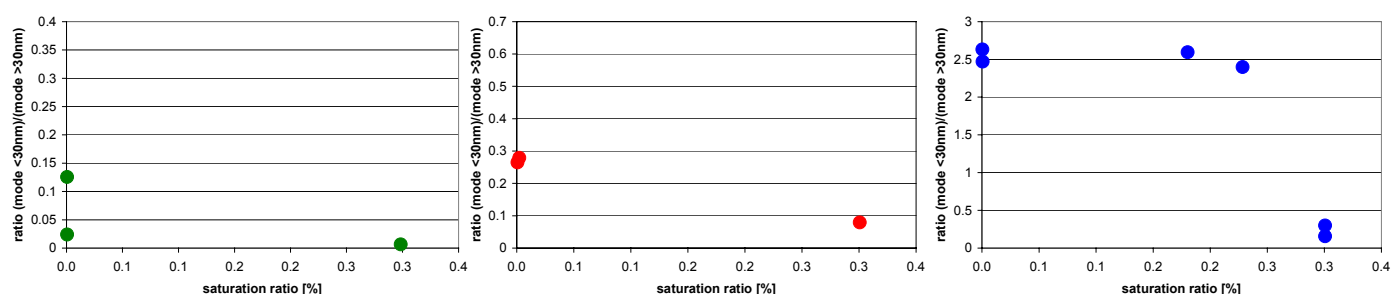

Fig. 5. Effect of the investigated organic compounds on the nucleation mode particles under condition A, B and C.

volved in the nucleation process under atmospheric conditions. Sakurai et al. (2003) reported that organic compounds from diesel nanoparticle was comprised of medium molecular weight with carbon numbers in the range from $\mathrm{C}_{24}$ to $\mathrm{C}_{32}$ for aliphatic hydrocarbons. However, our objective of this laboratory study is to identify the functional groups that are involved in the nucleation process. Therefore, the volatility of the organic compounds only plays a minor relevance for the interpretation of our data.

An overview of the effect of the organic compounds on the nucleation mode is given in Fig. 5. To compare the strength of nucleation, the ratio of the maximum number concentra- 
condition A $\left(\mathrm{T}=44.9{ }^{\circ} \mathrm{C}, \mathrm{RH}=36.3 \%\right) \quad$ condition $\mathrm{B}\left(\mathrm{T}=44.3^{\circ} \mathrm{C}, \mathrm{RH}=81.2 \%\right) \quad$ condition $\mathrm{C}\left(\mathrm{T}=34.7{ }^{\circ} \mathrm{C}, \mathrm{RH}=31.6 \%\right)$
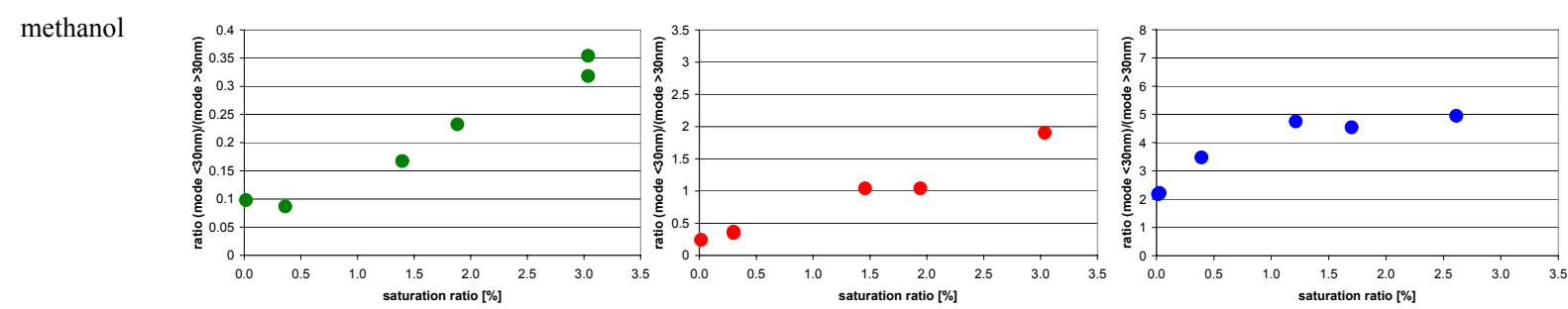

2-propanol
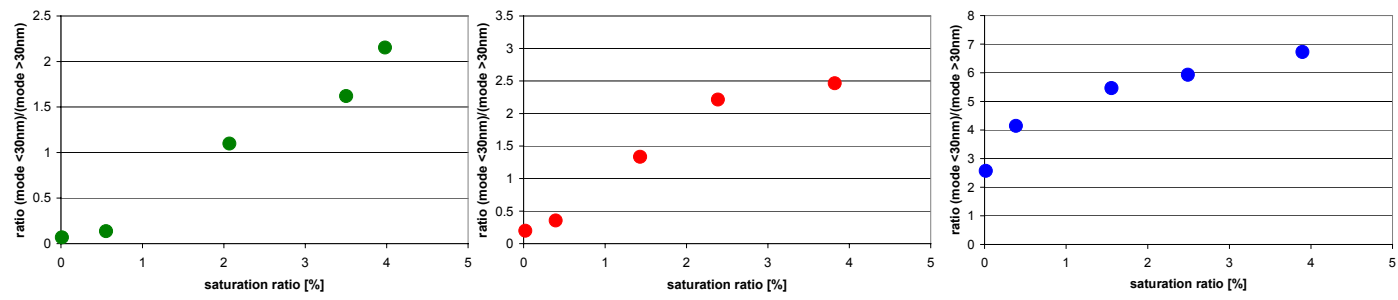

1-butanol
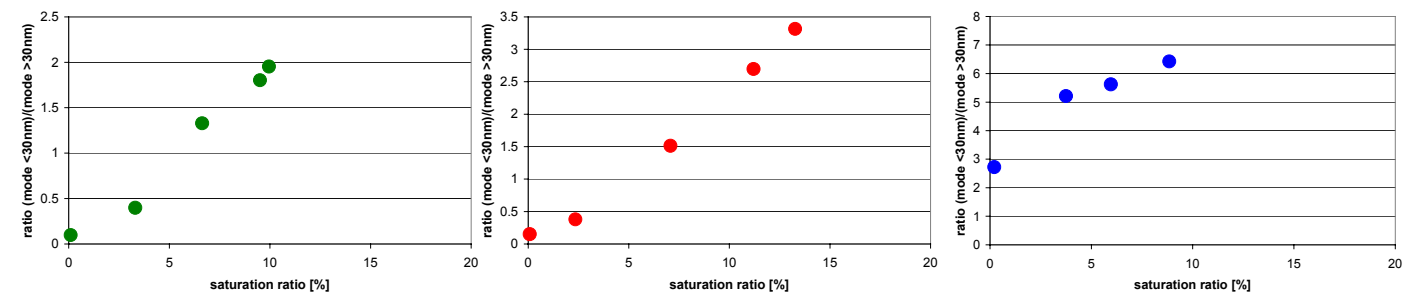

1-hexanol
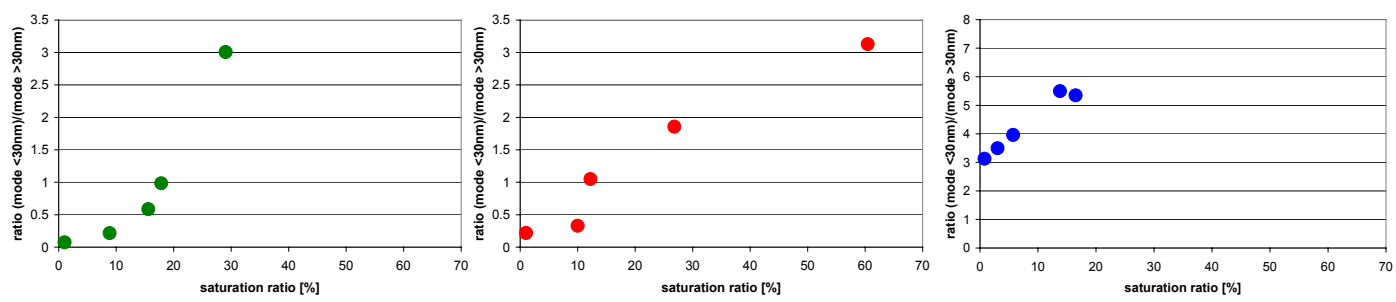

Fig. 5. Continued.

tions in the nucleation mode to the accumulation mode was calculated. The repeatability of the nucleation mode particles throughout the same test series is given in Fig. 5 for the four alcohols methanol, 2-propanol, 1-butanol, and 1hexanol. All alcohols were tested on the same day without turning off the engine. The test was started with condition B. As soon as stable sampling conditions were achieved, the concentration of the first alcohol was varied. Before the next alcohol was tested, SMPS scans were recorded without adding any alcoholic vapor. As illustrated in Fig. 5, the mode ratio of nucleation to soot particles was repeated each time before testing the next alcohol when no alcoholic vapor (saturation ratio $=0$ ) was added. The test procedure was analogue for the conditions $\mathrm{A}$ and $\mathrm{C}$. The mode ratio of nucleation to soot particles varied without alcoholic vapor (saturation ratio $=0$ ) in a small range under these conditions. Therefore, the nucleation mode particles were found to be stable under all conditions (A, B and C) within a time period of at least one hour.

\subsubsection{Aliphatic hydrocarbons}

The effect on nucleation mode particles was investigated for two aliphatic hydrocarbons hexane and cyclohexane. For both compounds, no effect was observed on the particles in the nucleation mode though the concentration in the dilution air was increased up to 8000 ppm (see Fig. 5). However, due to their high volatility, the saturation ratio remained always below $0.41 \%$. Besides the low saturation ratio, little interaction of these hydrophobic molecules with the main nucleation mode particles (water and sulfuric acid) exists.

\subsubsection{Aromatic compounds}

Toluene was chosen due to its high volatility compared to other polyaromatic compounds. Toluene influenced the nucleation mode particles under all conditions investigated, but only at the highest toluene concentration. Similar to the effect of humidity, the nucleation process was more affected when no or a weak nucleation mode existed in the begin- 

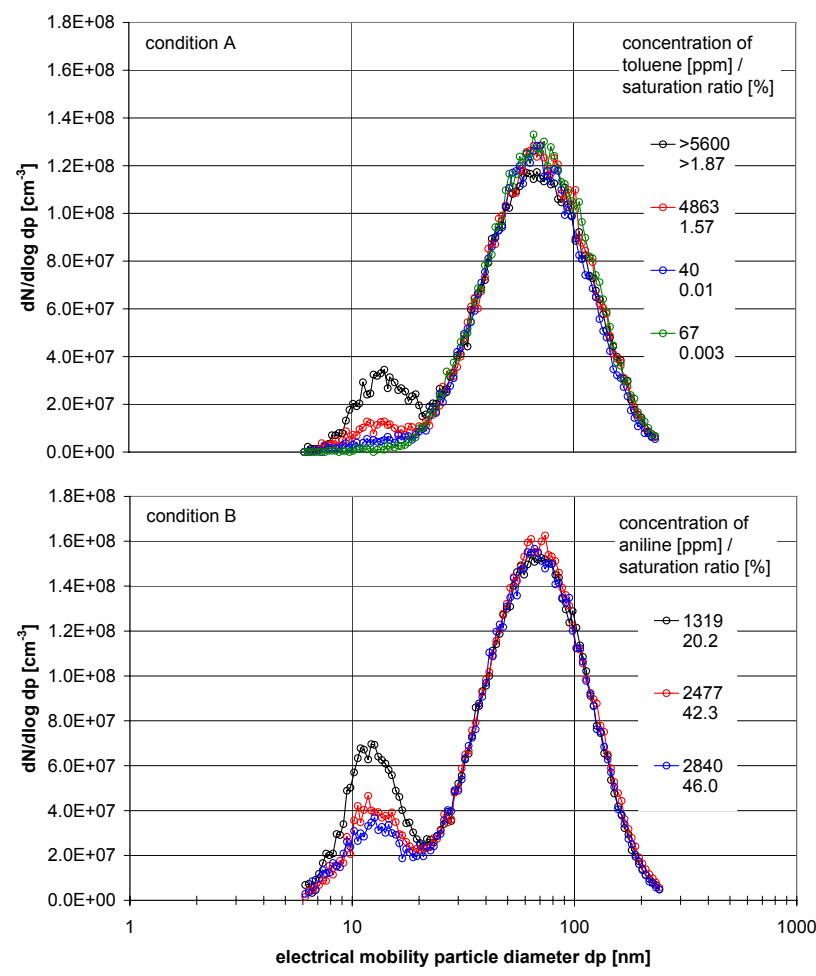

Fig. 6. Particle size distribution in the presence of aromatic compounds. The effects on the nucleation mode particles are presented for toluene (top panel) and aniline (bottom panel) under condition A $\left(\mathrm{T}=44.9^{\circ} \mathrm{C}, \mathrm{RH}=36.3 \%\right)$ and $\mathrm{B}\left(\mathrm{T}=44.3^{\circ} \mathrm{C}, \mathrm{RH}=81.2 \%\right)$, respectively.

ning as under conditions $\mathrm{A}\left(\mathrm{T}=44.9^{\circ} \mathrm{C}, \mathrm{RH}=36.3 \%\right)$ and $\mathrm{B}$ $\left(\mathrm{T}=44.3^{\circ} \mathrm{C}, \mathrm{RH}=81.2 \%\right)$ than for a strong nucleation mode as under condition $\mathrm{C}\left(\mathrm{T}=34.7^{\circ} \mathrm{C}, \mathrm{RH}=31.6 \%\right)$. Interestingly, toluene was capable of triggering a nucleation mode under condition A $\left(\mathrm{T}=44.9^{\circ} \mathrm{C}, \mathrm{RH}=36.3 \%\right)$ when no spontaneous nucleation occurred (see Fig. 6, top panel). Obviously, the hydrophobic toluene associates with the nucleation mode particles. Following a suggestion by Tobias et al. (2001), a two-phase system of the hydrophobic compounds and water/sulfuric acid is proposed because it is unlikely that an association takes place between toluene and water/sulfuric acid. It likely seems that the organic phase was mainly created by the added toluene. Compared to other factors affecting the nucleation process, e.g. humidity, the increased nucleation mode particles due to the addition of toluene were moderate. Therefore, hydrophobic compounds with vapor pressures comparable to or higher than toluene $(38 \mathrm{hPa}$ at $25^{\circ} \mathrm{C}$ ) are assumed to be irrelevant for the nucleation process in diluted diesel exhaust.

For aniline (see Fig. 6, bottom panel), nucleation mode particles were not influenced under condition $\mathrm{C}\left(\mathrm{T}=34.7^{\circ} \mathrm{C}\right.$, $\mathrm{RH}=31.6 \%$ ). A reduction of nucleation mode particles appeared under conditions $\mathrm{A}\left(\mathrm{T}=44.9^{\circ} \mathrm{C}, \mathrm{RH}=36.3 \%\right)$ and $\mathrm{B}$

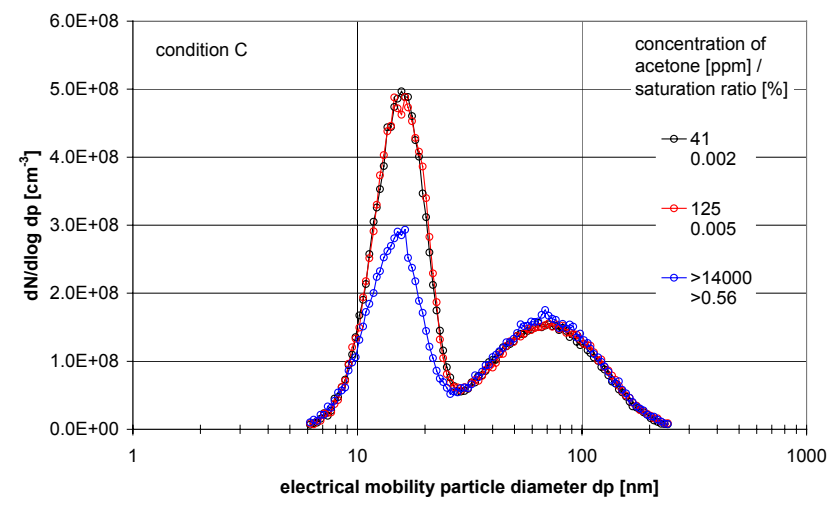

Fig. 7. Particle size distribution in the presence of acetone. Reduction of the nucleation mode particles occurred under condition $\mathrm{C}$ $\left(\mathrm{T}=34.7^{\circ} \mathrm{C}, \mathrm{RH}=31.6 \%\right)$.
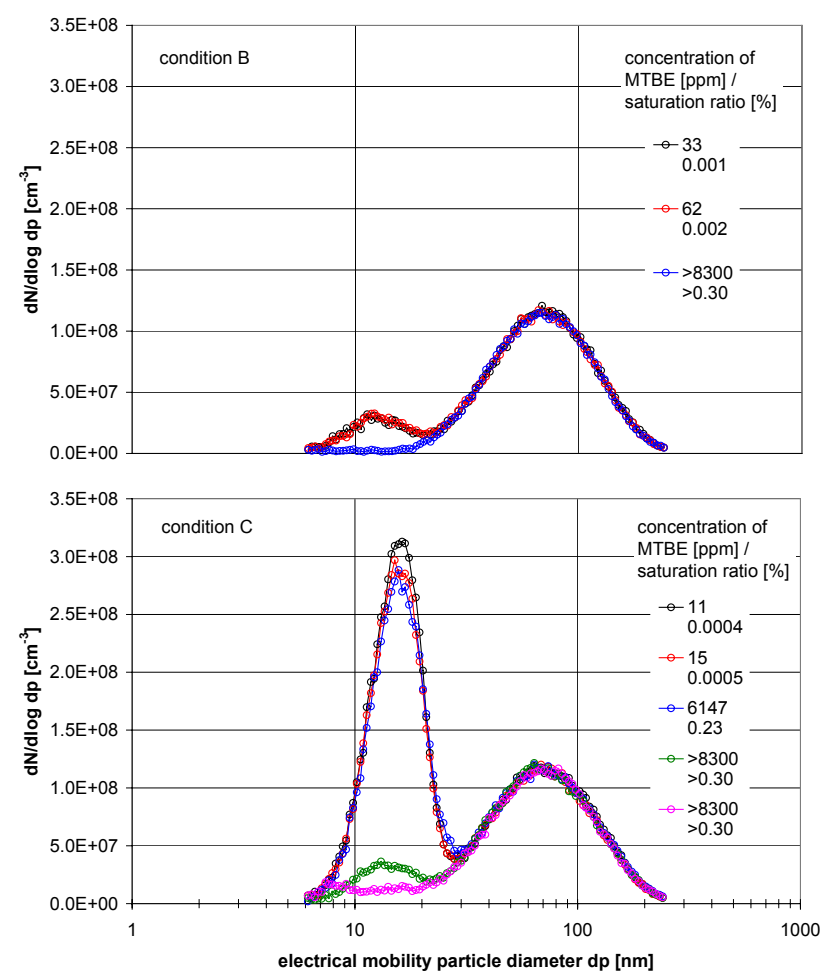

Fig. 8. Particle size distribution in the presence of $\mathrm{MTBE}$ under condition $\mathrm{B}\left(\mathrm{T}=44.3^{\circ} \mathrm{C}, \mathrm{RH}=81.2 \%\right)$, and $\mathrm{C}\left(\mathrm{T}=34.7^{\circ} \mathrm{C}\right.$, $\mathrm{RH}=31.6 \%$ ) on top panel and on bottom panel, respectively. In both cases the nucleation mode particles were reduced.

$\left(\mathrm{T}=44.3^{\circ} \mathrm{C}, \mathrm{RH}=81.2 \%\right)$. Since the reduction was weak and not confirmed under condition $\mathrm{C}\left(\mathrm{T}=34.7^{\circ} \mathrm{C}, \mathrm{RH}=31.6 \%\right)$, we conclude that the effect of aniline on nucleation mode particles is of minor relevance.

\subsubsection{Acetone}

Acetone was chosen due to its high volatility. Without pre-existing nucleation mode particles under condition A 


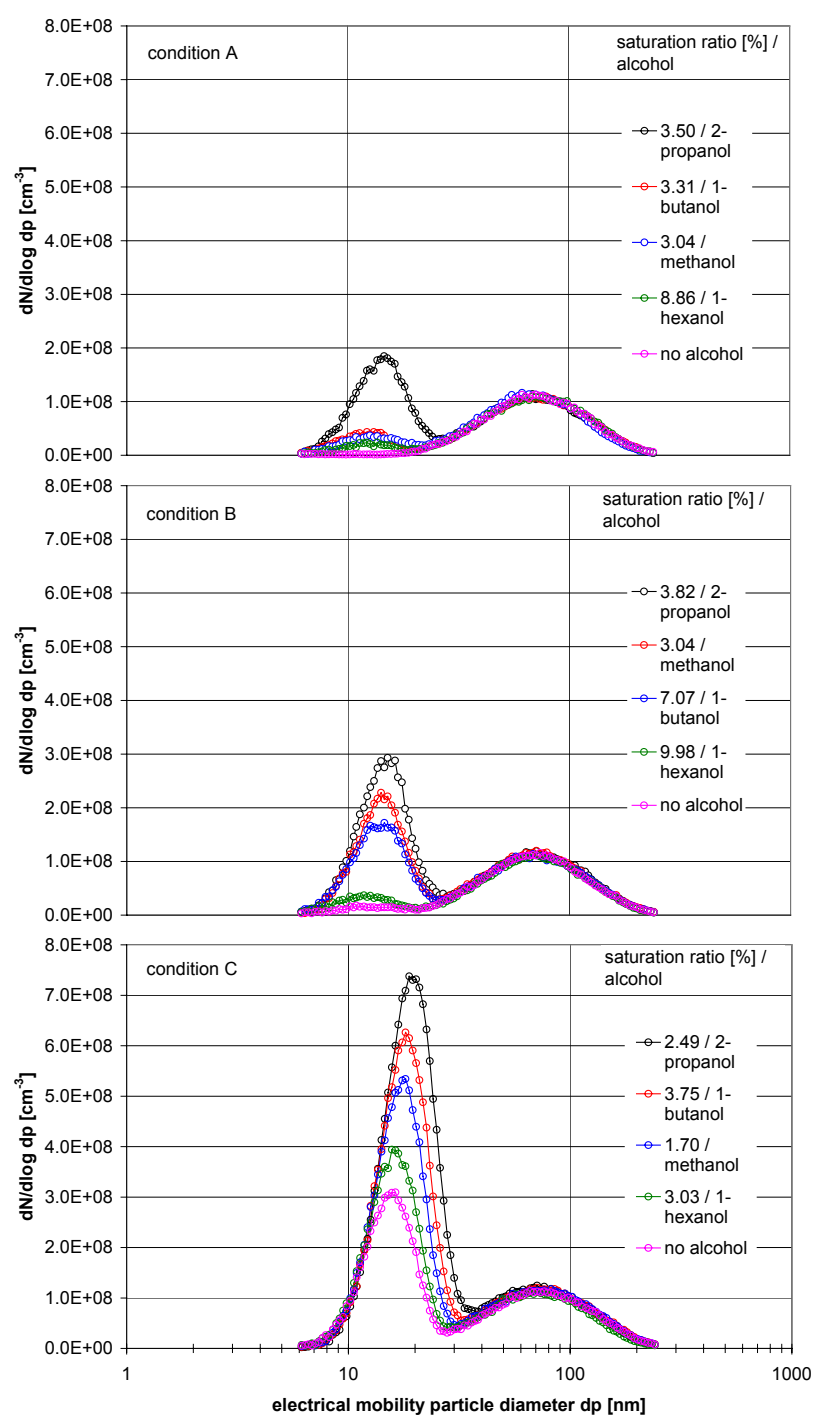

Fig. 9. Particle size distribution in the presence of methanol, 2-propanol, 1-butanol, and 1- hexanol under all three conditions A $\left(\mathrm{T}=44.9^{\circ} \mathrm{C}, \mathrm{RH}=36.3 \%\right), \mathrm{B}\left(\mathrm{T}=44.3^{\circ} \mathrm{C}, \mathrm{RH}=81.2 \%\right)$, and $\mathrm{C}$ $\left(\mathrm{T}=34.7^{\circ} \mathrm{C}, \mathrm{RH}=31.6 \%\right)$.

$\left(\mathrm{T}=44.9^{\circ} \mathrm{C}, \mathrm{RH}=36.3 \%\right)$, no effect on the nucleation was detected with addition of the compound. The effect of acetone was relatively weak and consisted in a decrease of nucleation mode particles with increasing acetone concentration in the sample under condition $\mathrm{B}\left(\mathrm{T}=44.3^{\circ} \mathrm{C}, \mathrm{RH}=81.2 \%\right)$ and $\mathrm{C}\left(\mathrm{T}=34.7^{\circ} \mathrm{C}, \mathrm{RH}=31.6 \%\right)$. As an example, condition $\mathrm{C}$ $\left(\mathrm{T}=34.7^{\circ} \mathrm{C}, \mathrm{RH}=31.6 \%\right)$ is depicted in Fig. 10.

\subsubsection{MTBE}

Due to its high relevance as a gasoline additive, MTBE was chosen. MTBE leads to more complete combustion due to the oxygen contained in the molecule (Poulopoulos and Philippopoulos, 2003). The nucleation mode parti-

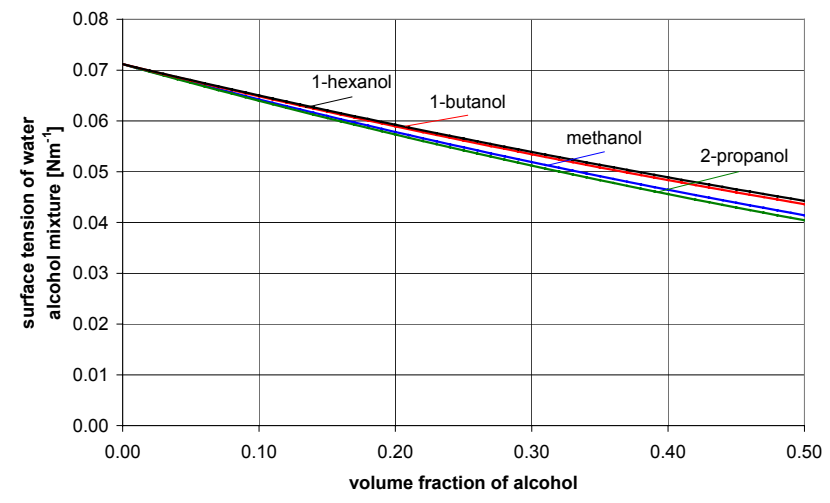

Fig. 10. Surface tension of water-alcohol mixtures versus on the alcohol volume concentration.

Table 5. Water solubility of the investigated alcohols (CRC-press, 1985).

\begin{tabular}{ll}
\hline alcohol & $\begin{array}{l}\text { water solubility, } \\
20^{\circ} \mathrm{C}\end{array}$ \\
\hline $\begin{array}{l}\text { methanol } \\
\text { 2-propanol }\end{array}$ & $\begin{array}{l}\text { completely miscible } \\
\text { completely miscible }\end{array}$ \\
1-butanol & $77 \mathrm{~g} \mathrm{1}^{-1}$ \\
\hline
\end{tabular}

cles showed a strong decrease as soon as the MTBE concentration was increased. Similar to acetone, no nucleation mode particles occurred with addition of MTBE under condition $\mathrm{A}\left(\mathrm{T}=44.9^{\circ} \mathrm{C}, \mathrm{RH}=36.3 \%\right)$. The nucleation was completely removed under condition $\mathrm{B}\left(\mathrm{T}=44.3^{\circ} \mathrm{C}, \mathrm{RH}=81.2 \%\right.$; see Fig. 8, top panel) and nearly suppressed under condition $\mathrm{C}\left(\mathrm{T}=34.7^{\circ} \mathrm{C}, \mathrm{RH}=31.6 \%\right.$; see Fig. 8 , bottom panel).

We do not have a satisfactory explanation for the reduction of nucleation mode particles with acetone and MTBE. MTBE is an inert compound that is often used as a solvent in chemical reactions and thus, no chemical reaction with any reactive combustion product is expected.

\subsubsection{Alcohols}

A selection of alcohols with increasing hydrophobicity was chosen, methanol, 2-propanol, 1-butanol, and 1-hexanol. When alcohol was added to the dilution air, an increase of nucleation mode particles was observed. In Fig. 9, a direct comparison of all four alcohols is depicted under all three conditions. The nucleation mode particles were increased in the following order: 2-propanol $>$ (1-butanol or methanol) $>1$ hexanol. Compared to condition $\mathrm{A}\left(\mathrm{T}=44.9^{\circ} \mathrm{C}, \mathrm{RH}=36.3 \%\right)$ and $\mathrm{B}\left(\mathrm{T}=44.3^{\circ} \mathrm{C}, \mathrm{RH}=81.2 \%\right)$, the relative increase of nucleation mode particles was much less pronounced under condition $\mathrm{C}\left(\mathrm{T}=34.7^{\circ} \mathrm{C}, \mathrm{RH}=31.6 \%\right)$. To explain the variation of 
the nucleation process within the alcohols, the surface tension and water solubility of the alcohols were considered in more detail. Since the alcohols investigated have a conspicuously lower surface tension than water, a surface tension reduction of the nucleation mode particles is expected in the presence of the alcohols. The reduction of surface tension as a function of the alcohol fraction is depicted in Fig. 10 for the alcohols investigated. The surface tensions of the wateralcohol mixtures were calculated by the method of Tamura (Tamura et al., 1955). The hydrophilic hydroxyl group interacts via hydrogen bonds with the water phase while the hydrophobic rest of the alcohol is directed away from the droplet and reduced the surface tension. A reduction of surface tension increases the concentration of nucleation mode particles since the barrier to nucleate is reduced. The highest increase in nucleation occurred for 2-propanol followed by methanol, 1-butanol, and 1-hexanol. In Table 5 the water solubility of the alcohols are documented. Methanol and 2-propanol, containing a short hydrophobic chain, are miscible with water and thus, a stronger nucleation is expected than for the more hydrophobic 1-butanol and 1-hexanol. The observed differences of nucleation mode particles can be explained by the water solubility and the surface tension for 2-propanol versus 1-hexanol, 1-butanol, and methanol, for 1butanol versus 1-hexanol, and for methanol versus 1-hexanol (see Fig. 9). In all these cases, an increasing water solubility and a decreasing surface tension led to stronger nucleation. Nevertheless, the experimental results obtained for methanol and 1-butanol cannot be explained by the water solubility and surface tension since both alcohols had a similar effect on the nucleation mode particles.

\section{Conclusions}

The role of organic vapors in the dilution air of diesel exhaust was investigated at constant vehicle speed. Three different settings of conditions A $\left(\mathrm{T}=44.9^{\circ} \mathrm{C}, \mathrm{RH}=36.3 \%\right)$, $\mathrm{B}\left(\mathrm{T}=44.3^{\circ} \mathrm{C}, \mathrm{RH}=81.2 \%\right)$, and $\mathrm{C}\left(\mathrm{T}=34.7^{\circ} \mathrm{C}, \mathrm{RH}=31.6 \%\right)$ were defined by the two crucial nucleation parameters, sample humidity and sample temperature. All relevant dilution parameters were controlled in a narrow range. It has to be noted that a total dilution ratio of 80 applied in this study might be lower than under real world conditions. Increased humidity initiated nucleation at the higher sample temperature and increased the existing nucleation mode at the lower sample temperature. As soon as the humidity initiated the nucleation process, the concentration of nucleation particles showed a linear correlation with relative humidity of the sample. The increase of nucleation mode particles at a sample temperature of $44.9^{\circ} \mathrm{C}$ was about $40 \%$ higher than at a sample temperature of $34.7^{\circ} \mathrm{C}$.

It was observed that organic compounds played a key role in nucleation. Because there is little knowledge of the chemical composition of the organic compounds involving in the formation of nucleation particles, we studied a broad selection of organic compounds. Aliphatic hydrocarbons (hexane and cyclohexane) turned out to be without effect on the nucleation process due to their high volatility. Only high concentrations of toluene led to an increase of nucleation mode particles. However, hydrophobic compounds without any functional groups and with vapor pressure equal or higher than toluene are unlikely to substantially contribute to the nucleation mode particles of diluted diesel exhaust. No uniform effect was observed on the nucleation mode particles when aniline was added into the dilution air. However, the effect was weak under all conditions and thus, aniline plays a minor role in the formation and growth of nucleation mode particles in diluted diesel exhaust. Alcohols generally increased nucleation mode particles. Two parameters may affect the potential of nucleation, reduction of surface tension and water solubility. With exception of the comparison between methanol and 1-butanol, the experimental results can be explained by the water solubility and surface tension: Increasing water solubility and decreasing surface tension led to stronger nucleation. 2-propanol, with the highest reduction in surface tension and water miscibility, increased nucleation most. The lower potential for nucleation of the water miscible methanol can be explained by the lower reduction of the surface tension compared to 2-propanol. Nucleation mode particles were less influenced by the more hydrophobic 1-hexanol. Although 1-hexanol and 1-butanol reduce the surface tension to a comparable extent, 1-butanol increased the concentration of nucleation mode particles significantly more than 1-hexanol. A possible reason for this finding could be the 13 times higher water solubility of 1-butanol. Acetone and MTBE reduced nucleation mode particles. We presently do not have a satisfactory explanation for this behavior. Further work has to be undertaken to understand the influence of organic compounds in reduction of nucleation mode particles in more detail.

Acknowledgements. This project was funded by the Swiss Federal Office for Education and Science (BBW). We thank R. Crockett from EMPA for critical review.

Edited by: M. Ammann

\section{References}

Abdul-Khalek, I. S., Kittelson, D. B., and Brear, F.: The influence of dilution conditions on diesel exhaust particle size distribution measurements, SAE Technical Paper Series, No. 1999-01-1142, 1999.

CRC-press: CRC Handbook of chemistry and physics, Boca Raton, FL, CRC Press, 1985.

Donaldson, K., Li, X. Y., and MacNee, W.: Ultrafine (nanometre) particle mediated lung injury, J. Aerosol. Sci., 29, 553-560, 1998.

Giebl, H., Berner, A., Reischl, G., Puxbaum, H., Kasper-Giebl, A., and Hitzenberger, R.: CCN activation of oxalic and malonic acid 
test aerosols with the University of Vienna cloud condensation nuclei counter. J. Aerosol. Sci., 33, 1623-1634, 2002.

Hegg, D. A., Gao, S., Hoppel, W., Frick, G., Caffrey, P., Leaitch, W. R., Shantz, N., Ambrusko, J., and Albrechcinski, T.: Laboratory studies of the efficiency of selected organic aerosols as $\mathrm{CCN}$, Atmos. Res., 58, 155-166, 2001.

Kerminen, V. M., Virkkula, A., Hillamo, R., Wexler, A. S., and Kulmala, M.: Secondary organics and atmospheric cloud condensation nuclei production, J. Geophys. Res.-Atmos., 105, 92559264, 2000.

Khalek, I. A., Kittelson, D. B., and Brear, F.: Nanoparticle growth during dilution and cooling of diesel exhaust: Experimental investigation and theoretical assessment, SAE Technical Paper Series, No. 2000-01-0515, 2000.

Kilgour, J. D., Rattray, N. J., Foster, J., Soames, A., and Hext, P.M.: Pulmonary responses and recovery following single and repeated inhalation exposure of rats to polymeric methylene diphenyl diisocyanate aerosols, J. Appl. Toxicol., 22, 371-385, 2002.

Kim, C. S. and Jaques, P. A.: Respiratory dose of inhaled ultrafine particles in healthy adults, Philos. Trans. R. Soc. Lond. Ser. AMath. Phys. Eng. Sci., 358, 2693-2705, 2000.

Kim, D., Gautam, M., and Gera, D.: Parametric studies on the formation of diesel particulate matter via nucleation and coagulation modes, J. Aerosol. Sci., 33, 1609-1621, 2002.

Kittelson, D. B.: Engines and nanoparticles: A review, J. Aerosol. Sci., 29, 575-588, 1998.

Kittelson, D. B.: Particle measurement methodology: Comparison of on-road and lab diesel particle size distribution, Proceedings of the 6th International ETH-Conference on Nanoparticle Measurements 19.-21. August, 2002.

Krähenbühl, M. A. and Gmehling, J.: Vapor-pressures of methyl tert-butyl ether, ethyl tert-butyl ether, isopropyl tert-butyl ether, tert-amyl methyl-ether, and tert-amyl ethyl ether. J. Chem. Eng. Data, 39, 759-762, 1994.

Lange, N. A. and Dean, J. A.: Lange's handbook of chemistry, McGraw-Hill, New York, 1973.

Maricq, M. M., Chase, R. E., and Podsiadlik, D. H.: Vehicle exhaust particle size distributions: A comparison of tailpipe and dilution tunnel measurements, SAE Technical Paper Series, No. 1999-01$1461,1999$.

Mathis, U.: Influencing parameters of nanoparticle formation from diesel exhaust, Proceedings of the 6th International ETHConference on Nanoparticle Measurements 19.-21. August, 2002.

Mikkanen, P., Moisio, M., Keskinen, J., Ristimäki, J., and Marjamäki, M.: Sampling method for particle measurements of vehicle exhaust, SAE Technical Paper Series, No. 2001-01-0219, 2001.

Mohr, M., Jaeger, L. W., and Boulouchos, K.: The influence of engine parameters on particulate emissions, MTZ worldwide, 62, 686-692, 2001.

Napari, I., Kulmala, M., and Vehkamaki, H.: Ternary nucleation of inorganic acids, ammonia, and water, J. Chem. Phys., 117, 8418-8425, 2002.

Ntziachristos, L., Samaras, Z., Pistikopoulos, P., and Kyriakis, N.: Statistical analysis of diesel fuel effects on particle number and mass emissions, Environ. Sci. Technol., 34, 5106-5114, 2000.

Oberdörster, G.: Pulmonary effects of inhaled ultrafine particles, Int. Arch. Occup. Environ. Health, 74, 1-8, 2001.
Petrovic, S., Urch, B., Brook, J., Datema, J., Purdham, J., Liu, L., Lukic, Z., Zimmerman, B., Tofler, G., Downar, E., Corey, P., Tarlo, S., Broder, I., Dales, R., and Silverman, F.: Cardiorespiratory effects of concentrated ambient PM2.5: A pilot study using controlled human exposures, Inhal. Toxicol., 12, 173-188, 2000.

Poling, B. E., Prausnitz, J. M., and O'Connell, J. P.: The properties of gases and liquids, McGraw-Hill, New York, 2001.

Pope, C. A.: Review: Epidemiological basis for particulate air pollution health standards, Aerosol Sci. Technol., 32, 4-14, 2000.

Poulopoulos, S. G. and Philippopoulos, C. J.: The effect of adding oxygenated compounds to gasoline on automotive exhaust emissions, J. Eng. Gas. Turbines Power-Trans. ASME, 125, 344-350, 2003.

Sakurai, H., Tobias, H. J., Park, K., Zarling, D., Docherty, S., Kittelson, D. B., McMurry, P. H., and Ziemann, P. J.: On-line measurements of diesel nanoparticle composition and volatility, Atmos. Environ., 37, 1199-1210, 2003.

Seinfeld, J. H. and Pandis, S. N.: Atmospheric chemistry and physics from air pollution to climate change, Wiley, New York, 1998.

Shi, J. P. and Harrison, R. M.: Investigation of ultrafine particle formation during diesel exhaust dilution, Environ. Sci. Technol., 33, 3730-3736, 1999.

Soskolne, C. L., Zeighami, E. A., Hanis, N. M., Kupper, L. L., Herrmann, N., Amsel, J., Mausner, J. S., and Stellman, J. M.: Laryngeal-cancer and occupational exposure to sulfuric-acid, Am. J. Epidemiol., 120, 358-369, 1984.

Swenberg, J. A. and Beauchamp, R. O.: A review of the chronic toxicity, carcinogenicity, and possible mechanisms of action of inorganic acid mists in animals, Crit. Rev. Toxicol., 27, 253-259, 1997.

Sydbom, A., Blomberg, A., Parnia, S., Stenfors, N., Sandstrom, T., and Dahlen, S. E.: Health effects of diesel exhaust emissions, Eur. Resp. J., 17, 733-746, 2001.

Tamura, M., Kurata, M., and Odani, H.: Practical method for estimating surface tensions of solutions, Bull. Chem. Soc. Jpn., 28, 83-88, 1955.

Tobias, H. J., Beving, D. E., Ziemann, P. J., Sakurai, H., Zuk, M., McMurry, P. H., Zarling, D., Waytulonis, R., and Kittelson, D. B.: Chemical analysis of diesel engine nanoparticles using a nano-DMA/thermal desorption particle beam mass spectrometer, Environ. Sci. Technol., 35, 2233-2243, 2001.

Vogt, R., Scheer, V., Casati, R., and Benter, T.: On-road measurement of particle emission in the exhaust plume of a diesel passenger car, Environ. Sci. Technol., 37, 4070-4076, 2003.

Yu, F. Q.: Chemiions and nanoparticle formation in diesel engine exhaust, Geophys. Res. Lett., 28, 4191-4194, 2001.

Yu, F. Q.: Chemiion evolution in motor vehicle exhaust: Further evidence of its role in nanoparticle formation, Geophys. Res. Lett., 29, art. no.-1717, 2002.

Yu, S. C.: Role of organic acids (formic, acetic, pyruvic and oxalic) in the formation of cloud condensation nuclei $(\mathrm{CCN})$ : a review, Atmos. Res., 53, 185-217, 2000.

Zhang, K. M. and Wexler, A. S.: A hypothesis for growth of fresh atmospheric nuclei, J. Geophys. Res.-Atmos., 107, art. no. 4577, 2002. 